\title{
Developing best practice for infilling daily river flow data
}

\author{
Catherine L. Harvey, Harry Dixon and Jamie Hannaford
}

Centre for Ecology and Hydrology, Wallingford, UK

Email:harr@ceh.ac.uk

\begin{abstract}
Complete river flow time series are indispensable to the sustainable management of water resources and even very short gaps can severely compromise data utility. Suitably-flagged flow estimates, derived via judicious infilling, are thus highly beneficial. The UK National River Flow Archive provides stewardship of and access to daily river flow records from over 1500 gauging stations and, whilst the majority are sensibly complete, historical validation reveals a significant quantity of gaps. A full assessment of the suitability of existing techniques for infilling such gaps is lacking. This paper therefore presents an appraisal of various simple infilling techniques, including regression, scaling and equipercentile analysis, according to their ability to generate daily flow estimates for 25 representative UK gauging stations. All of the techniques rely upon data transfer from donor stations and results reveal that the equipercentile and multiple regression approaches perform best. Case studies offer further insight and an example of infilling is presented, along with areas of future study. The results demonstrate the potential for developing generic infilling methodologies to ensure a consistent and auditable approach towards infilling, which could find wider application both within the UK and internationally.
\end{abstract}

\section{Introduction}

River flow records are a vitally important asset, critical to the sustainable management of water resources worldwide and serving as both indicators of past hydrological variability and fundamental contributors to hydrological models for future behaviour prediction. The completeness of such records is a crucial component of their utility. Even very short gaps preclude the calculation of important summary statistics, such as monthly runoff totals or $n$-day minimum flows, and inhibit the analysis and interpretation of flow variability. Consequently, in many cases, including suitably flagged estimates of flow is preferable to leaving gaps (Marsh, 2002).

Within the UK, the National River Flow Archive (NRFA; http://www.ceh.ac.uk/data/nrfa) acts as the main hydrometric archive, collating data from all principal monitoring network operators. Daily mean river flows are assimilated for over 1500 gauging stations and these data are stored, analysed and disseminated to a wide range of users (Dixon, 2010). Whilst the majority of these flow records have high percentage completeness (Marsh and Hannaford, 2008), historical validation reveals a significant number of gaps within the time series, ranging in length from a single day to a number of months. Such gaps in recorded flows are an inevitable consequence of factors such as essential gauging station maintenance, equipment malfunction, human error, changes in instrumentation and data processing issues.

A previously observed decline in the completeness of river flow data submitted to the NRFA (Marsh, 2002) can in part be attributed to a lack of standardised infilling guidance which, in its absence, discouraged the infilling of gaps. The introduction of a Service Level Agreement between the NRFA and its data providers in 2002, the aims of which include advancing the completeness of data submitted to the archive, has been reflected in a demonstrable improvement in completeness (Dixon, 2010). Nevertheless, historical data gaps remain and short sequences of missing daily mean flows (which appear readily amenable to infilling) regularly occur in data submitted to the NRFA. This highlights a pressing need for informed infilling guidance, to ensure consistency in approach towards data gaps. Simple, quick-to-apply infilling techniques that perform well across an extensive range of catchments could therefore find wide applicability, limiting the resources required to infill data to an appropriate accuracy whilst significantly improving the overall utility of time series. There is thus a strong need to assess existing infilling techniques in terms of their ability to estimate observed flows. Such an appraisal could be translated into guidance for hydrometric measuring authorities, as well as potentially holding relevance for both the wider river flow data user community within the UK and internationally. Such guidance would not be applicable to all occurrences of missing data; in particular, it would not be appropriate for extreme flows, which warrant separate attention.

Existing infilling techniques, developed either exclusively for infilling or alternatively for record extension, were assessed for applicability (Table 1). The term 'target' indicates the gauging station record that requires infilling. Many techniques rely upon data transfer from other gauging stations, a widespread approach within hydrology, and these stations are referred to as 'donors'. What constitutes a good donor is arguably a research topic in its own right, but common considerations include proximity and similarity (in terms of responsiveness and catchment physiography) to the target (Rees, 2008). Where available, multiple donors can enhance the likelihood of capturing the many influences affecting a target, but a single donor could be adequate if located very close to the target or on a major upstream tributary (Hughes and Smakhtin, 1996).

To discern whether or not an infilling technique is widely applicable, techniques need to be tested across a broad range of scenarios. To date, the vast majority of studies have limited their analyses to a small number of case-study targets (for example: Gyau-Boakye and Schultz, 1994; Elshorbagy et al., 2000), but the marked variability in hydrological regimes and prevalence of anthropogenic influences across the UK 


\begin{tabular}{|c|c|c|}
\hline Method & Summary & Example reference \\
\hline $\begin{array}{l}\text { Manual } \\
\text { inference }\end{array}$ & $\begin{array}{l}\text { Gaps are infilled through visual comparison with } \\
\text { donor flows. Accuracy should be fairly assured for } \\
\text { short gaps with no rainfall events, or alternatively } \\
\text { for longer gaps during stable recessions, but other } \\
\text { scenarios would lead to increased difficulty and } \\
\text { subjectivity. }\end{array}$ & Rees (2008) \\
\hline $\begin{array}{l}\text { Serial } \\
\text { interpolation } \\
\text { techniques }\end{array}$ & $\begin{array}{l}\text { These include linear, polynomial and spline } \\
\text { interpolation and are likely to only be successful } \\
\text { throughout stable periods. }\end{array}$ & Rees (2008) \\
\hline $\begin{array}{l}\text { Scaling } \\
\text { factors }\end{array}$ & $\begin{array}{l}\text { Donor flows are multiplied by a scaling factor, such } \\
\text { as the ratio of the donor and target catchment areas } \\
\text { or a weighting based upon the linear distance } \\
\text { between the target and donor. }\end{array}$ & Kottegoda and Elgy (1977) \\
\hline $\begin{array}{l}\text { Equipercentile } \\
\text { technique }\end{array}$ & $\begin{array}{l}\text { The percentile value of the donor flow on any given } \\
\text { day is assumed equal to the percentile value of the } \\
\text { target flow. Flow gaps are estimated by calculating } \\
\text { the donor flow percentile values and using the } \\
\text { existing target flow data to derive the flow } \\
\text { equivalent to this percentile value at the target. }\end{array}$ & $\begin{array}{l}\text { Hughes and Smakhtin } \\
\text { (1996) }\end{array}$ \\
\hline $\begin{array}{l}\text { Linear } \\
\text { regression }\end{array}$ & $\begin{array}{l}\text { A regression equation between the target and a } \\
\text { donor is derived, commonly via the least squares } \\
\text { method, and used to calculate absent target flows. } \\
\text { Flows may first be transformed, for example, via } \\
\text { the logarithmic transformation. }\end{array}$ & Hirsch (1982) \\
\hline $\begin{array}{l}\text { Hydrological } \\
\text { modelling }\end{array}$ & $\begin{array}{l}\text { This can vary from black-box modelling, whereby } \\
\text { the inputs to the model are related to the outputs } \\
\text { with no consideration of the processes involved, to } \\
\text { the much more complex process-based models and } \\
\text { use of artificial neural networks. }\end{array}$ & Khalil et al. (2001) \\
\hline
\end{tabular}

necessitates consideration of a higher number of targets. In this study, techniques will therefore be tested on a large sample of representative UK gauging stations.

Previous studies have focused on either a single technique or a small number of techniques all belonging to the same general approach (for instance, regression techniques: Hirsch, 1982; scaling techniques: Kottegoda and Elgy, 1977). An unprecedented aspect of this study is the inclusion of a large number of techniques, spanning a variety of statistical formulations.

The relative performance of infilling techniques can be compared through infilling artificially created gaps (for example, Gyau-Boakye and Schultz, 1994), but this methodology is highly dependent upon the period in which the gaps are established. An alternative approach, followed by this study, is to compare the ability of techniques to simulate entire target flow records (for example, Elshorbagy et al., 2000), providing an indication of techniques which can be expected to perform better for any given gap.

\section{Data and methodology}

A representative sample of 25 NRFA target stations was selected from around the UK, incorporating both very responsive (including urban) and groundwater-fed rivers (Figure 1). Associated primary and secondary donors were selected from both nested and neighbouring catchments, since network density means geographically local donors are difficult to find in some parts of the country. Donors were chosen using NRFA catchment and station metadata, according to factors such as location, base flow index (BFI; Gustard et al., 1992) and regime similarity (Table 2).

Ten infilling techniques, embracing equipercentile, scaling and regression approaches, were tested according to their ability to simulate the target daily mean flow records (Table 3). Hydrological modelling of target flow series was

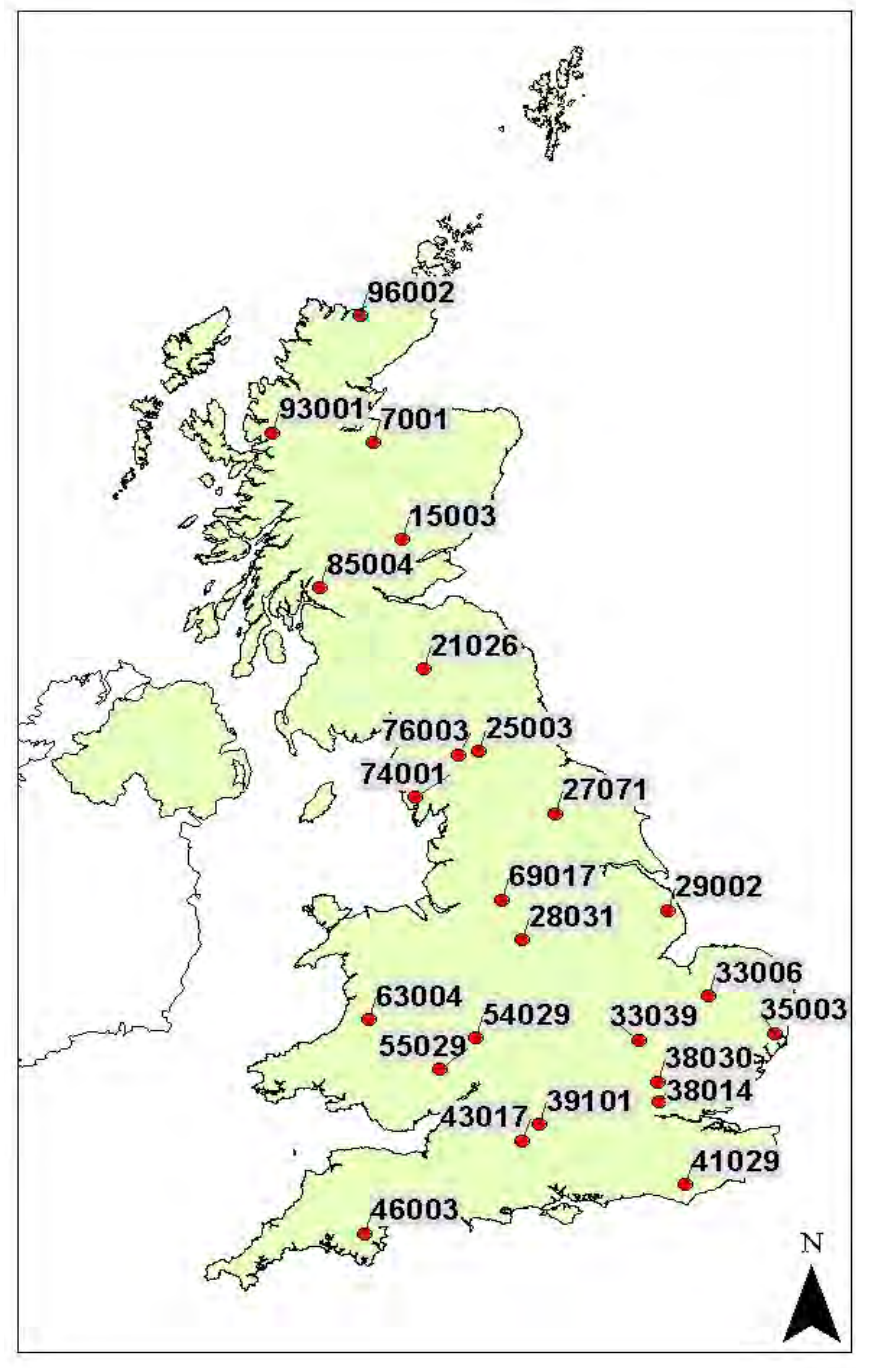

Figure 1 Map of the UK showing the target station locations by NRFA ID. 
Table 2 Target and associated donor stations.

\begin{tabular}{|c|c|c|c|c|c|}
\hline $\begin{array}{l}\text { Target } \\
\text { station } \\
\text { NRFA ID }\end{array}$ & River and location & $\begin{array}{l}\text { Catchment } \\
\text { area }\left(\mathrm{km}^{2}\right)\end{array}$ & $B F I$ & $\begin{array}{l}\text { Primary } \\
\text { donor }\end{array}$ & $\begin{array}{c}\text { Secondary } \\
\text { donor }\end{array}$ \\
\hline 7001 & Findhorn at Shenachie & 415.6 & 0.36 & 7002 & 7004 \\
\hline 15003 & Tay at Caputh & 3210 & 0.64 & 15007 & 15006 \\
\hline 21026 & Tima Water at Deephope & 31 & 0.26 & 21017 & 21007 \\
\hline 25003 & Trout Beck at Moor House & 11.4 & 0.14 & 23009 & 76014 \\
\hline 27071 & Swale at Crakehill & 1363 & 0.46 & 27007 & 27034 \\
\hline 28031 & Manifold at Ilam & 148.5 & 0.54 & 28008 & 28046 \\
\hline 29002 & Great Eau at Claythorpe Mill & 77.4 & 0.89 & 29003 & 29001 \\
\hline 33006 & Wissey at Northwold & 274.5 & 0.82 & 33007 & 33019 \\
\hline 33039 & Bedford Ouse at Roxton & 1660 & 0.57 & 33037 & 33015 \\
\hline 35003 & Alde at Farnham & 63.9 & 0.37 & 35002 & 35013 \\
\hline 38014 & Salmon Brook at Edmonton & 20.5 & 0.29 & 38022 & 38021 \\
\hline 38030 & Beane at Hartham & 175.1 & 0.75 & 38004 & 33033 \\
\hline 39101 & Aldbourne at Ramsbury & 53.1 & 0.97 & 39077 & 39037 \\
\hline 41029 & Bull at Lealands & 40.8 & 0.38 & 41016 & 41003 \\
\hline 43017 & West Avon at Upavon & 84.6 & 0.71 & 53013 & 53002 \\
\hline 46003 & Dart at Austins Bridge & 247.6 & 0.52 & 46005 & 46008 \\
\hline 54029 & Teme at Knightsford Bridge & 1480 & 0.54 & 54008 & 55014 \\
\hline 55029 & Monnow at Grosmont & 354 & 0.50 & 56012 & 55013 \\
\hline 63004 & Ystwyth at Pont Llolwyn & 169.6 & 0.40 & 55008 & 63001 \\
\hline 69017 & Goyt at Marple Bridge & 183 & 0.53 & 69007 & 69015 \\
\hline 74001 & Duddon at Duddon Hall & 85.7 & 0.30 & 74007 & 74008 \\
\hline 76003 & Eamont at Udford & 396.2 & 0.52 & 76004 & 76015 \\
\hline 85004 & Luss Water at Luss & 35.3 & 0.28 & 86001 & 85003 \\
\hline 93001 & Carron at New Kelso & 137.8 & 0.26 & 4005 & 4006 \\
\hline 96002 & Naver at Apigill & 477 & 0.42 & 2002 & 3002 \\
\hline
\end{tabular}

Table 3 Infilling techniques tested by this study. In order to account for any flow records containing zero flows, the log-transformation took the form of $\ln (f l o w+1)$. Techniques were applied to datasets comprising days when observed flows existed for both the target and primary donor (single donor techniques) or all three stations (dual donor techniques).

\begin{tabular}{lll}
\hline Acronym & Name & Details \\
\hline LR & Linear regression & Least-squares linear regression between target and primary donor. \\
LR Log & Linear regression log & As above but using log-transformed flows. \\
M1 & MOVE.1 & MOVE.1 regression between target and primary donors (Hirsch, 1982). \\
M1 Log & MOVE.1 log & As above but using log-transformed flows. \\
Equi & Equipercentile & $\begin{array}{l}\text { Equipercentile technique applied using percentiles derived } \\
\text { from the primary donor flows. }\end{array}$ \\
CA & Catchment area scaling & $\begin{array}{l}\text { Catchment area scaling technique applied using the catchment areas } \\
\text { of the target and primary donor. }\end{array}$ \\
LTM & Long-term mean & $\begin{array}{l}\text { Long-term mean scaling technique applied using long-term mean flow } \\
\text { values of the target and primary donor flows. }\end{array}$ \\
MR & Multiple regression & $\begin{array}{l}\text { Least-squares linear regression between target and both donors. } \\
\text { As above but using log-transformed flows. }\end{array}$ \\
W.Equi & Multiple regression log & $\begin{array}{l}\text { As aighted } \\
\text { Equipercentile technique applied using each of the donor records }\end{array}$ \\
\hline
\end{tabular}

not considered since, despite its potential to offer highly accurate estimates, current methods are too resource-intensive for rapid application to a large number of stations. Model calibration requirements also constrain portability between catchments. Simple manual inference and serial interpolation techniques were also omitted as, despite their undoubted practical utility, they are heavily reliant upon subjective decisions and cannot be easily automated and objectively compared within a testing framework. A final criterion was to utilise only river flow data, avoiding dependence on other datasets (in particular, catchment rainfall) which may not always be readily available to users.

Technique performance was evaluated according to three commonly used indices, the choice of which was informed by the recommendations of studies which have assessed performance indictors (Legates and McCabe, 1999; Moriasi et al., 2007):
Nash-Sutcliffe Model Efficiency Coefficient (NSE; Nash and Sutcliffe, 1970):

$$
\text { NSE }=1-\frac{\Sigma(\text { observed flow }- \text { estimated flow })^{2}}{\Sigma(\text { observed flow }- \text { mean }(\text { observed flows }))^{2}}
$$

Values can range from $-\infty$ to 1 , with higher values implying greater accuracy and values below zero indicating that the estimated series is less accurate than if the mean of the observed series had been used. The statistic is widely used and, as a standardised statistic, has the advantage of being easily comparable across different catchments.

\section{Root Mean Square Error (RMSE):}

RMSE $=\sqrt{\Sigma(\text { observed flow }- \text { estimated flow })^{2}}$ 
Lower values indicate better performance, but comparing values between different targets is limited since differing variance between targets is not accounted for.

\section{Percent Bias (PBIAS):}

$$
\text { PBIAS }=\frac{\Sigma(\text { observed flow }- \text { estimated flow })}{\Sigma(\text { observed flows })} \times 100
$$

This index highlights consistent under- or over-estimation of target flows, which would likely correlate to poorer performance.

In addition to the above statistics, the means of the absolute residuals between the observed and estimated flows were calculated for each target station and compared using the non-parametric Wilcoxon test, to indicate whether a given technique generated estimated series with significantly lower means of residuals than those generated by other techniques.

\section{Results}

The overall performance of the techniques is demonstrated via box plots of the NSE and PBIAS values derived for the 25 series estimated by each technique (Figure 2), whilst their performance for each individual target is illustrated via bar plots of the NSE values for each series and technique (Figure 3). The RMSE values indicate analogous results to the NSE values so the latter was chosen to present results since, as a standardised statistic, it is easier to compare across the different targets.

In terms of the NSE value box plots, the interquartile ranges and bottom whiskers exceed 0.5 for all of the techniques, albeit to varying degrees. Some techniques have outlying values which fall below zero, results which are important for differentiating between how widely applicable the techniques are. The most favourable techniques are

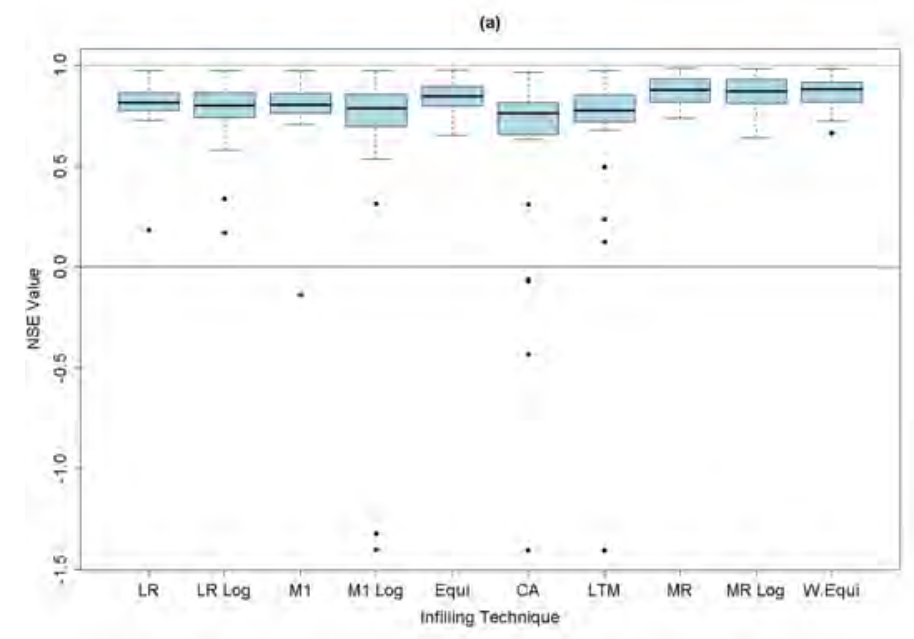

(b)

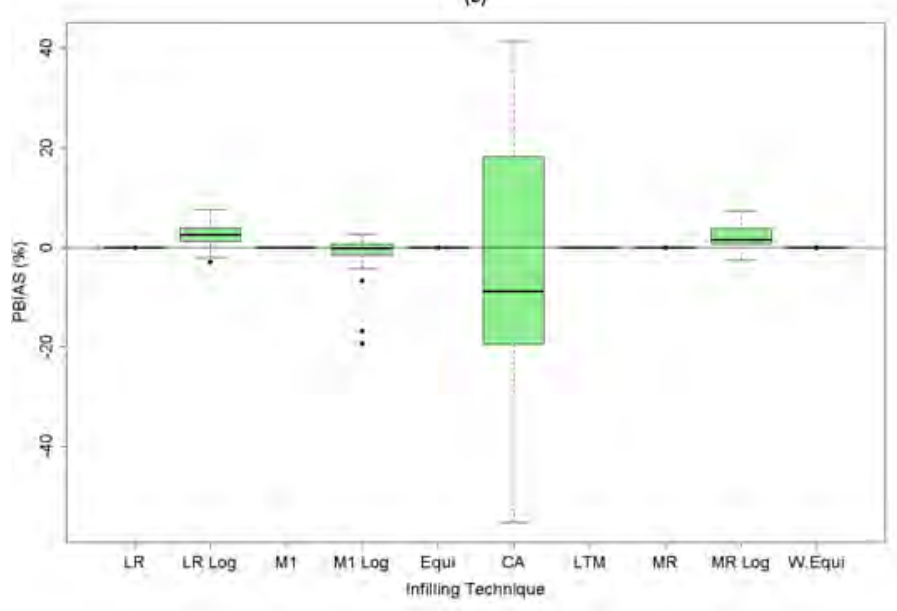

Figure 2 Box plots of (a) NSE and (b) PBIAS values for the 25 series estimated by each technique. Whiskers extend to the most extreme values which are no more than 1.5 multiplied by the interquartile range away from the box.

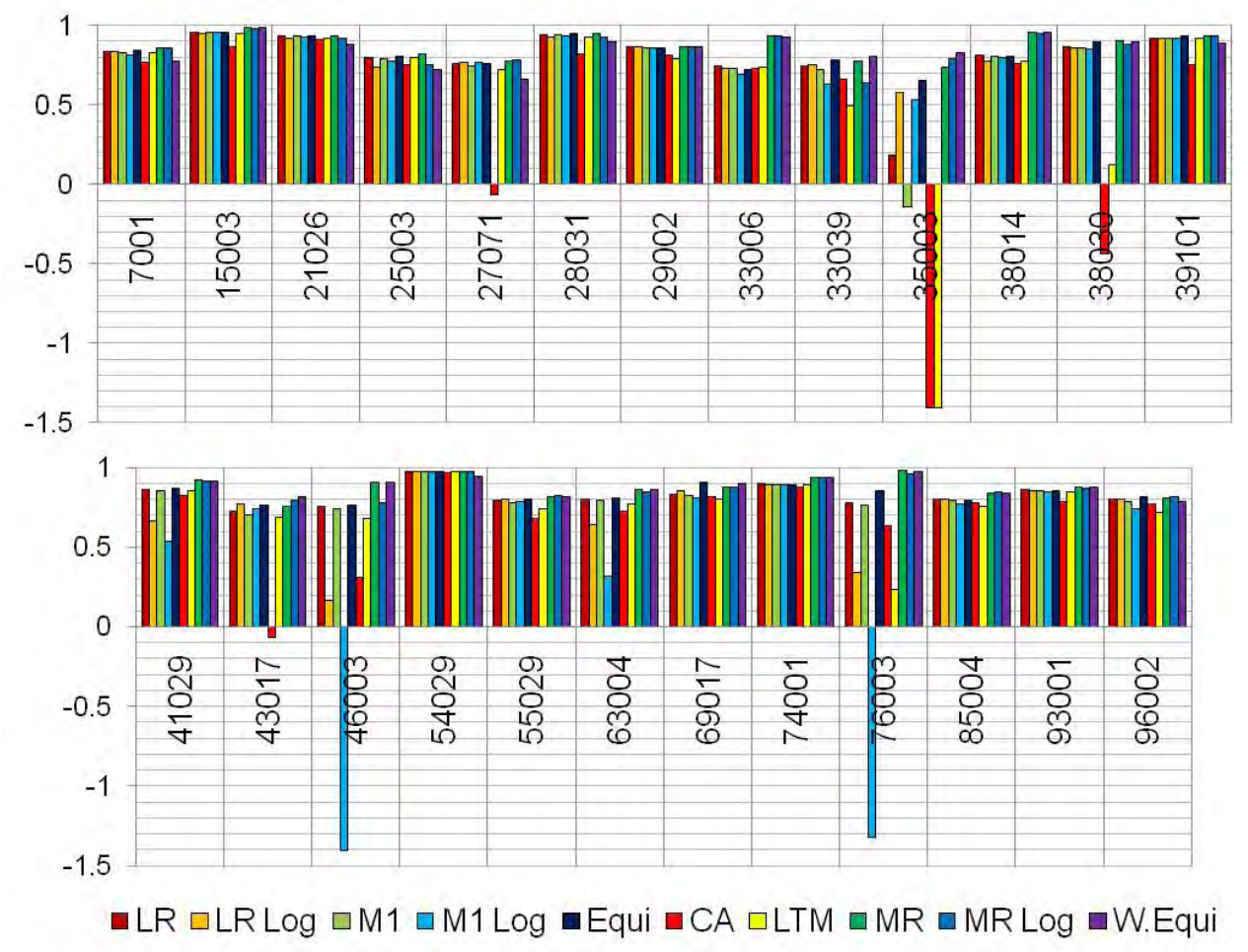

Figure 3. Bar plots of NSE values for each target and each technique. 
the equipercentile and multiple donor techniques, none of which have outliers falling below 0.5 and all of which have lower quartile, median and upper quartile values of a higher magnitude than the other techniques. Not only do these techniques therefore have wider application, but they also produce estimated series of greater accuracy.

The PBIAS values are generally of low magnitude for the majority of techniques, except the CA technique, which is conspicuous for its heavily biased estimates. Those techniques based upon log-transformed flows also exhibit some bias. This can be linked to failure of these techniques to maintain the mean of the observed series in their estimates.

For some individual targets, the techniques perform very similarly, although to differing degrees. For example, all techniques produce NSE values exceeding 0.94 for target 54029 and between 0.72 and 0.82 for target 25003 . For other targets, there is much greater variability in technique performance (for example, 33039 and 76003), a finding which is further explored later (see first case study). In certain cases, the multiple donor techniques offer clear improvement (for example, stations 33006 and 38014).

There are particular stations for which specific techniques lead to distinctly lower NSE values, most prominent of these being M1 Log for targets 46003 and 76003 (see second case study), CA and LTM for targets 35003 and 38030 and CA for targets 27071 and 43017 . Overall, CA is a comparatively poorer technique, having most of the lowest NSE values associated with it as well as the highest PBIAS values. Moreover, its NSE values have the lowest lower quartile, median and upper quartile magnitudes of all the techniques, in addition to the greatest number of both outliers and outliers falling below zero.

The results of the Wilcoxon significance testing (Figure 4) further reinforce the findings so far. The equipercentile and multiple donor techniques more frequently produce significantly lower means of residuals than the other techniques, whilst all of the techniques outperform the CA technique for the vast majority (in some cases all) of the targets.

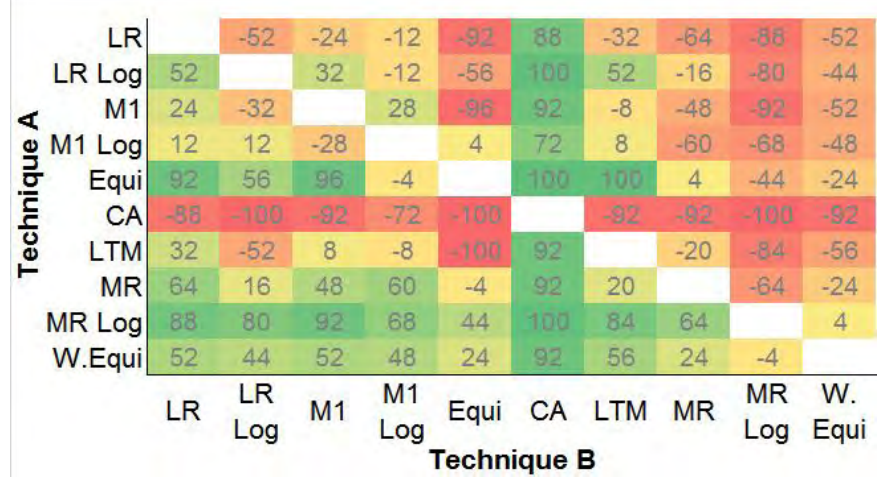

Figure 4 Results of significance testing. Values at the intersection of technique $A$ (y-axis) and technique $B$ (x-axis) indicate the percentage more (positive values) or less (negative values) of targets for which A produced significantly lower means of residuals compared to $B$ (at the $5 \%$ level). Values are colourcoded from red for $-100 \%$ to green for $+100 \%$.

\section{Discussion}

Assessing the ability of the chosen infilling techniques to generate estimated target flow series has revealed certain techniques to noticeably outperform, or in the case of the catchment area scaling technique, underperform the other techniques for specific target stations. This is a key outcome, since it associates wider applicability to the former techniques and highlights the value of using a large sample of target gauging stations. The catchment area scaling technique essentially seems too simple to capture the influences affecting the target and even very closely related stations seldom exhibit a linear relationship with catchment area (Hughes and Smakhtin, 1996).

In some cases, data transfer from multiple donors offers an improvement over a single donor, endorsing the general argument of multiple donors being more capable of capturing the many influences affecting target flows. In many other cases, however, the single and multiple techniques yield sensibly identical performances, such that there is no marked advantage to including multiple donors. With respect to the influence of donor choice on technique performance, there are two clear results. Firstly, for the five targets with NSE values exceeding 0.9 under all single donor techniques, the primary donors are either upstream, downstream or nested compared to the targets and the multiple donor techniques offer no further improvement in these cases. Secondly, none of the techniques succeed in producing estimated series with NSE values exceeding 0.9 when neither donor is upstream, downstream or nested. This suggests that the relative locations of the donors could be a critical factor in technique performance and work is ongoing to investigate this further. Future work will also interpret the results according to base flow index, to determine whether a target's catchment regime affects technique performance, as well as whether base flow index is a reliable factor in donor identification.

The general conclusions that can be drawn from the overall results could contribute to broad infilling guidelines, but assessing technique performance for individual targets exposes other areas of discussion. Two case studies are therefore now presented, the first looking at using localised data and the second covering technique performance at different flow magnitudes. An infilling example is also shown.

\section{First case study: Salmon Brook at Edmonton (38014)}

The Salmon Brook at Edmonton gauging station (38014) represents a small, impervious catchment in the south of the UK. The site originally comprised a compound broadcrested weir structure, known to be less effective than the 1980 replacement flat V weir (Marsh and Hannaford, 2008). This change is reflected in a marked quality difference between the pre-1980 and post-1980 data. Prior to 1980 , the poorer data quality results in an adverse impact on the relationship between the target and donor flows, confirmed when comparing the NSE values derived under each of the techniques for the full datasets to those of the post-1980 data (Table 4). There is less of an increase in performance for the multiple donor techniques as, although the primary donor record extends back to 1954, the secondary donor record only starts in 1971.

Table 4. Comparison of NSE values for full and post-1980 datasets when estimating target series 38014.

\begin{tabular}{lll}
\hline Technique & Full Dataset & Post-1980 Dataset \\
\hline LR & 0.813 & 0.869 \\
LR Log & 0.777 & 0.852 \\
M1 & 0.804 & 0.864 \\
M1 Log & 0.796 & 0.861 \\
Equi & 0.809 & 0.863 \\
CA & 0.760 & 0.846 \\
LTM & 0.774 & 0.825 \\
MR & 0.955 & 0.965 \\
MR Log & 0.948 & 0.957 \\
W.Equi & 0.955 & 0.963 \\
\hline
\end{tabular}


This is therefore a clear example of when localising donor data can be expected to improve the accuracy of estimates for flow gaps. As well as the replacement or modification of gauging structures, the homogeneity of UK flow records has been affected by changes relating to instrumentation, land use and artificial influences. These may also necessitate the use of localised data and highlight the need to maintain comprehensive user guidance information alongside hydrometric records (Dixon, 2010). Other means of localising datasets are to consider wet and dry epochs separately (Hughes and Smakhtin, 1996) or to group flows according to the month or season that they correspond to, which has been demonstrated to offer significant improvement (Raman et al., 1995). Ongoing work by the authors is exploring such approaches, by applying the same infilling techniques to both full and localised datasets.

\section{Second case study: Eamont at Udford (76003)}

The Eamont at Udford gauging station (76003) in northwest England gauges a catchment artificially influenced by storage in lakes and reservoirs. In this case, the single donor techniques regressing log-transformed flows performed markedly more poorly than their counterparts regressing non-transformed flows. As would logically be expected, however, visual inspection of the estimated series intimates that log-transforming the flows can yield greater accuracy at lower flows, despite less accuracy at higher flows. By way of example, Figure 5 displays all regression-based estimates for a higher flow period and a lower flow period. The visual disparity between the MR and MR Log estimates is less apparent, but RMSEs for LR, M1 and MR are all lower (higher) during the higher (lower) flow period than those for LR Log, M1 Log and MR Log.

The RMSEs of the entire estimated series were calculated separately for lower and higher observed flows (Table 5). Better performance of regression-based techniques is evident at higher flows when flows are not transformed, whereas log-transforming flows gives equivalent or better performance than non-transforming flows at lower flows. Lower (higher) flows were simply defined as lower (higher) than the observed series mean, excluding the lowest (highest) $5 \%$ of flows, and varying these groupings could enhance this distinction. The RMSEs also imply larger residuals for higher compared to lower flows. The considerable discrepancies identified by the performance indicators between LR and LR

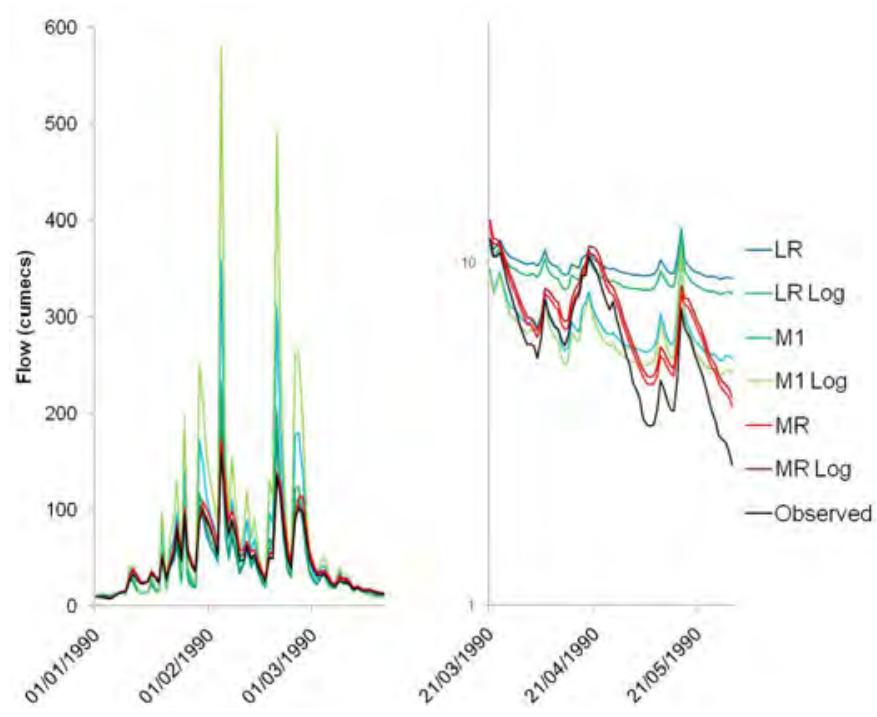

Figure 5 Estimated and observed flows at target 76003 during a higher flow (left panel, linear scale) and a lower flow period (right panel, logarithmic scale).
Table 5 RMSE values of estimates for target station 76003, derived via regression-based techniques and calculated separately according to the magnitude of the observed flows.

\begin{tabular}{lcccccc}
\hline $\begin{array}{l}\text { RMSE } \\
\text { Dataset }\end{array}$ & LR & LR Log & $M 1$ & $M 1$ Log & MR & MR Log \\
\hline Lower flows & 411.4 & 318.3 & 366.6 & 364.3 & 132.7 & 132.2 \\
Higher flows & 621.4 & 794.8 & 634.8 & 1070.0 & 204.9 & 239 \\
\hline
\end{tabular}

Log and M1 and M1 Log can thus be attributed to squaring the differences between the observed and estimated values, which attaches greater weight to larger differences and biases the indicators towards the better performance of LR and M1 at higher flows.

Ongoing work by the authors is investigating a novel methodology of grouping estimates according to flow magnitude and assessing technique performance separately for each group. This may allow easier identification of instances when particular techniques surpass others at certain flow magnitudes and could also isolate favourable technique combinations. A number of studies has previously advocated that a single technique is unlikely to be optimal for all occasions of missing data (for example: Hughes and Smakhtin, 1996; Gyau-Boakye and Schultz, 1994).

\section{Application example}

The South Tyne at Haydon Bridge (23004) is part of the UK benchmark catchment network, often used within climate change detection studies (for example: Hannaford and Marsh, 2008). As such, it is particularly important that its record be as complete as possible. A nearby upstream station at Featherstone (23006) is a suitable primary donor, also representing a natural flow regime of similar responsiveness. Due to artificial influences acting on other nearby stations, a secondary donor is more difficult to establish, therefore an infilling attempt will be made using the equipercentile technique, concluded as arguably the best of the single donor techniques.

In 1972, a low flow control was installed at Haydon Bridge, with low flows prior to this being of limited accuracy (Marsh and Hannaford, 2008), evident when inspecting the earlier record. Consequently, a localised target dataset of post-1971 flows was used. Equipercentile flow estimates were derived to infill a three-month long gap in the record in
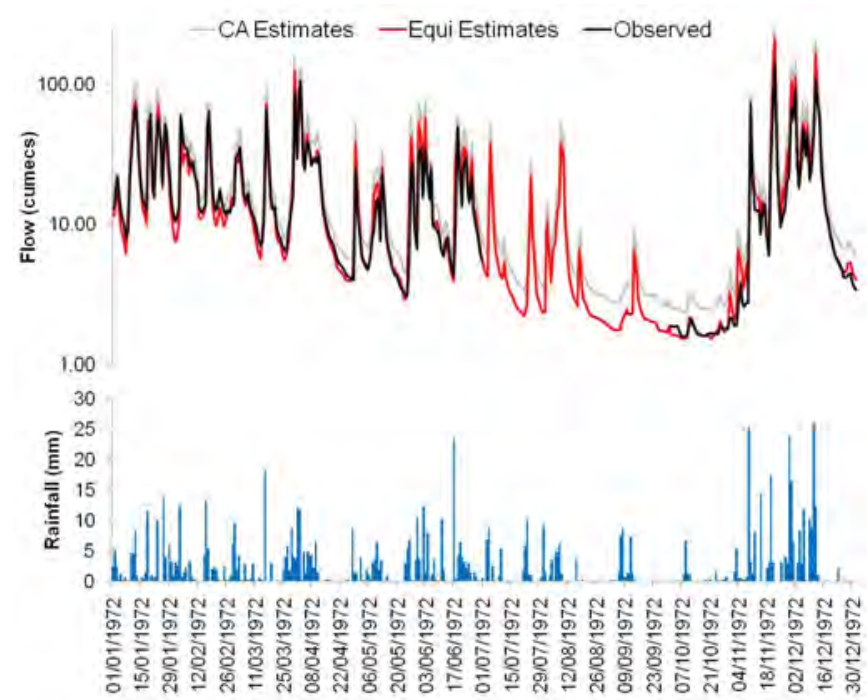

Figure 6 Top: Observed 1972 flows for the South Tyne at Haydon Bridge (23004) and estimated flows under equipercentile and CA techniques, based upon donor of South Tyne at Featherstone (23006). Bottom: Rainfall from the Met Office rain gauge 14284. 
1972, which reflects the installation of this control (Figure 6). Catchment area estimates were also calculated, to offer comparison between better and poorer techniques.

This example serves to successfully illustrate the purpose of this study. It presents a data gap in a flow record which appears amenable to an infilling attempt, since a good donor exists and, based on recorded rainfall patterns and catchment response, the majority of the missing flows could be expected to be mid-range (estimates for the very low observed flows at the end of the gap should be treated with more caution as these infilling techniques are not suggested for estimating extreme low or high flows). A simple infilling technique is then applied, producing reliable infill estimates. The results of this study are also reflected, in that the equipercentile estimates clearly suggest greater accuracy than the CA estimates.

\section{Conclusion}

Complete flow records are a vitally important resource but difficult to attain, given the many ways in which data gaps can arise. Simple infilling techniques that can be rapidly deployed across large numbers of records would find wide applicability and be highly beneficial in improving consistency and confidence in the approach towards reducing data gaps.

This study has assessed ten techniques, all relying on single or multiple donor station data transfer, according to their ability to generate estimated flow series for 25 representative UK target stations. Key findings concern the importance of the geographical locations of donor stations relative to target stations and the overall better performance of the equipercentile and multiple donor techniques versus the overall poorer performance of the catchment area scaling technique. The aim of this study has not, however, been to pinpoint a single optimal technique, but to investigate the ranges of applicability of each of the techniques. Testing a large sample of stations has thus allowed identification of cases where there are notable discrepancies between technique performances, highlighting the wider applicability of certain techniques.

More detailed work is underway to examine issues such as the influence of donor station choice, the potential for techniques to perform differently at varying flow magnitudes and the improvement that localising datasets could offer. Case-by-case analysis will allow interpretation of results according to the different catchment characteristics and flow regimes of the target stations. Future work will also explore more applications of infilling, to further examine the practicalities of implementing the key findings of this study.

Backed by the support of national archives, hydrometric measuring agencies are often best placed to derive realistic flow estimates for data gaps, given their detailed knowledge of gauging stations. Within the UK, the findings of this study and future work will allow the development of general infilling guidance appropriate to the wide range of flow regimes that exist and embracing a range of techniques, with local hydrological conditions and the hydrometric experience of measuring agencies guiding the method choice and application. It is hoped that this research will therefore help initiate systematic infilling of contemporary flow data which, coupled with clear flagging of estimates, will greatly improve the utility of flow series to end users. Moreover, consistent infilling methodologies will facilitate retrospective improvement of key national flow records, through the infilling of gaps, correction of erroneous periods and reviewing existing estimates within historical data.
Outside the sphere of operational hydrometry, the adoption of a consistent and tested approach to river flow data infilling offers many potential benefits to scientists and practitioners, both within the UK and more widely. Finally, it must be emphasised that the ability of simple infilling techniques to generate reliable infill estimates, as illustrated by the infilling example presented within this study, does not replace the need to maximise the quality and completeness of observed data.

\section{Acknowledgements}

The authors would like to thank their colleague Terry Marsh at the Centre for Ecology and Hydrology for his assistance with this study. All data was sourced from the National River Flow Archive.

\section{References}

Dixon, H. 2010. Managing national hydrometric data: from data to information. In: Global Change - Facing Risks and Threats to Water Resources (Proceedings of the Sixth World FRIEND Conference, Fez, Morocco, October 2010). IAHS Publication no. 340. In Press.

Elshorbagy, A.A., Panu, U.S. and Simonovic, S.P. 2000. Group-based estimation of missing hydrological data: II. Application to streamflows. Hydrolog. Sci. J., 45, 867-880.

Gustard, A., Bullock, A. and Dixon, J.M. 1992. Low flow estimation in the United Kingdom. Institute of Hydrology Report No. 108.

Gyau-Boakye, P. and Schultz, G.A. 1994. Filling gaps in runoff time-series in West-Africa. Hydrolog. Sci. J., 39, 621-636.

Hannaford, J. and Marsh, T.J. 2008. High-flow and flood trends in a network of undisturbed catchments in the UK. Int. J. Climatol., 28, 1325-1338.

Hirsch, R.M. 1982. A comparison of four streamflow record extension techniques. Water Resour. Res., 15, 1781-1790.

Hughes, D.A. and Smakhtin, V. 1996. Daily flow time series patching or extension: A spatial interpolation approach based on flow duration curves. Hydrolog. Sci. J., 41, 851-871.

Khalil, M., Panu, U.S. and Lennox, W.C. 2001. Groups and neural networks based streamflow data infilling procedures. J. Hydrol., 241, 153-176.

Kottegoda, N.T. and Elgy, J. 1977. Infilling missing flow data. In: Morel-Seytoux, H.J. (ed). Modelling Hydrologic Processes. Water Resources Publications.

Legates, D.R. and McCabe Jr, G.J. 1999. Evaluating the use of "goodness-of-fit" measures in hydrologic and hydroclimatic model validation. Water Resour. Res., 35 , 233-241.

Marsh, T.J. 2002. Capitalising on river flow data to meet changing national needs - a UK perspective. Flow Measurement and Instrumentation, 13, 291-298.

Marsh, T.J. and Hannaford, J. (Eds). 2008. UK Hydrometric Register. Hydrological data UK series. Centre for Ecology \& Hydrology.

Moriasi, D.N., Arnold, J.G., Van Liew, M.W., Bingner, R.L., Harmel, R.D. and Veith, T.L. 2007. Model evaluation guidelines for systematic quantification of accuracy in watershed simulations. Trans. ASABE, 50, 885-900.

Nash, J.E. and Sutcliffe, J.V. 1970. River flow forecasting through conceptual models. Part 1: A discussion of principles. J. Hydrol., 10, 282-290. 
Raman, H., Mohan, S. and Padalinathan, P. 1995. Models for extending streamflow data: a case study. Hydrolog. Sci., 40, 381-393.

Rees, G. 2008. Hydrological data. In: Gustard, A. and Demuth, S. (eds). Manual on Low-flow Estimation and Prediction. Operational Hydrology Report No. 50. World Meteorological Organisation. 